\title{
Standardised tomato extract as an alternative to acetylsalicylic acid in patients with primary hypertension and high cardiovascular risk - a randomised, controlled trial
}

\author{
Beata Krasinska ${ }^{1}$, Angelika Osińska ${ }^{1}$, Maciej Osinski², Aleksandra Krasinska ${ }^{3}$, Piotr Rzymski ${ }^{4}$, \\ Andrzej Tykarski ${ }^{1}$, Zbigniew Krasiński ${ }^{5}$
}

\begin{abstract}
${ }^{1}$ Department of Hypertension, Angiology and Internal Diseases, Poznan University of Medical Sciences, Poznan, Poland

2Department of Obstetrics, Gynaecology and Gynaecological Oncology, Division of Reproduction, Poznan University of Medical Sciences, Poznan Poland ${ }^{3}$ Student Medical Faculty 1, Poznan University of Medical Sciences, Poznan, Poland ${ }^{4}$ Department of Environmental Medicine, Poznan University of Medical Sciences, Poznan, Poland

${ }^{5}$ Department of General and Vascular Surgery, Poznan University of Medical Sciences, Poznan, Poland
\end{abstract}

Submitted: 12 August 2017

Accepted: 16 August 2017

Arch Med Sci 2018; 14, 4: 773-780

DOI: https://doi.org/10.5114/aoms.2017.69864

Copyright (c) 2017 Termedia \& Banach

\section{Abstract}

Introduction: Cardiovascular (CV) diseases remain a leading global cause of death. It has been proven that the use of acetylsalicylic acid (ASA) in secondary prevention reduces the CV risk, while the benefits of ASA in primary prevention have recently been debated. The aim of the study was to compare the antiplatelet effect of standardised tomato extract (STE) and ASA in hypertensive patients with high CV risk.

Material and methods: The study involved high-risk patients with arterial hypertension $(\mathrm{AH})$ randomly assigned to one of two groups: group 1 included 33 patients receiving ASA and group 2 included 32 patients receiving STE. The platelet aggregation was determined using the VerifyNow analyser. Results: After 4 weeks of ASA treatment in group 1, a statistically significant reduction in aspirin reaction units (ARU) was observed $(p<0.001)$. However, the obese subgroup using ASA $(n=18)$ did not reveal a significant decrease in ARU $(p>0.05)$. After 4 weeks of STE treatment in the obese subgroup $(n$ $=14)$, significant declines in ARU by $8.6 \%(95 \% \mathrm{Cl}:-19.5$ to $-1.7 \% ; p<0.05)$ and in $\mathrm{P} 2 \mathrm{Y} 12$ reaction units (PRU) by $7.5 \%(95 \% \mathrm{Cl}:-17.6$ to $1.8 \% ; p<0.05)$ were observed.

Conclusions: The antiplatelet effect of STE in hypertensive patients may be weight dependent. The group with $\mathrm{AH}$ and obesity might have potentially benefitted from STE treatment.

Key words: anti-aggregation, arterial hypertension, high cardiovascular risk, obesity, diet supplement, standardised tomato extract.

\section{Introduction}

Reducing the process of platelet aggregation significantly decreases the risk of myocardial infarction and the total number of cardiovascular (CV) events [1, 2]. In patients with cardiovascular disease (CVD), antiplatelet
Corresponding author: Beata Krasinska MD, PhD Department of Hypertension, Angiology and Internal Diseases Poznan University of Medical Sciences $1 / 2$ Dluga St 61-848 Poznan, Poland Phone: +48603951984 E-mail: beata.bkrasinska@ gmail.com 
therapy reduces the risk of serious vascular events. Side effects, such as bleeding, are relatively small, so they are exceeded by the benefits of antiplatelet therapy in secondary prevention [3]. According to the $2013 \mathrm{ESH} / \mathrm{ESC}$ guidelines for the management of arterial hypertension, in patients with high and very high total CV risk, acetylsalicylic acid (ASA) administration should be considered in the treatment to reduce this CV risk [4]. It has already been well proven that the use of ASA in secondary prevention reduces the risk of major cardiovascular events, while the benefits of ASA in primary prevention have recently been debated [4]. According to the 2016 European Guidelines on CV prevention in clinical practice, ASA prophylaxis is not recommended in individuals who do not suffer from CVD, due to the increased risk of major bleeding [5]. Hence, it is important to look for alternative antiplatelet therapy in subjects with CV risk factors [6]. One of these alternative compounds could be a standardised extract of tomato. Standardised tomato extract (STE) has a strong multifactorial impact on platelet function: it affects the inhibition of ADP-mediated aggregation, thromboxane, collagen, von Willebrand factor, thrombin and inflammatory mediators. The effect of STE is reversible and it maintains a platelet activity level that allows aggregation in the case of vascular injury and does not cause side effects [7-15]. The available data support the thesis of the beneficial effect of the Mediterranean diet with a high content of vegetables (rich in tomatoes) and fruit due to its antiplatelet activity, which results in CV risk reduction [16-18].
It seems worthwhile to conduct a comparison of the less common STE with clinically recognised ASA. The aim of this study was to compare the antiplatelet effect of STE and ASA in hypertensive patients with high $\mathrm{CV}$ risk.

\section{Material and methods}

\section{Study design}

The study included 82 high-risk hypertensive patients (44 men and 38 women), aged 28-74 years, and it was conducted between July 2015 and February 2017 in the Department of Hypertension at the University of Medical Sciences in Poznan. Seventeen patients withdrew their consent during the study. The study was approved by the Local Bioethical Committee of Poznan University of Medical Sciences (permission no. 377/15) and was therefore performed in accordance with the ethical standards laid down in the 1964 Declaration of Helsinki and its later amendments. All patients undersigned written consent forms. The study was listed in the Registration and Results System and obtained the following ClinicalTrials. gov ID: NCT03206944. Patients with primary AH and high and very high total CV risk were randomised in a blinded fashion (the sealed envelope method) to one of two groups (4). Group 1 ASA included 33 patients who received ASA at a dose of $75 \mathrm{mg}$ in the morning. Group 2 STE included 32 patients receiving STE (ZAAX, Sequia, Poland) at a dose of $213 \mathrm{mg}$ orally in the morning. The patients had two visits, a baseline one and after

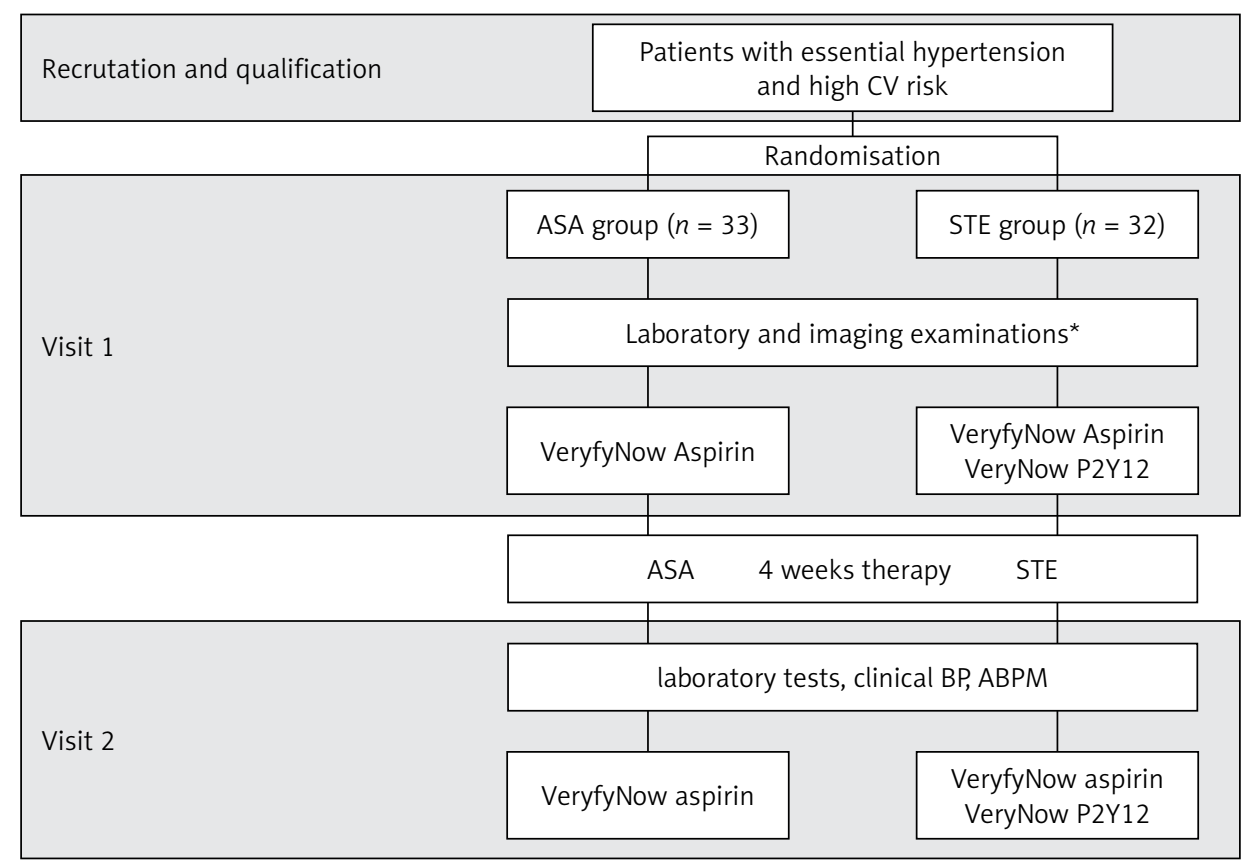

Figure 1 . Scheme of the study

*In each group: laboratory tests, abdominal ultrasound examination, abdominal CT scan, Doppler ultrasound of renal arteries, clinical BP $(3 x / 24 h), A B P M, E C G$, echocardiography, weight and body mass index assessment. 
4 weeks of treatment, according to the scheme presented in Figure 1. There were no changes in the concomitant treatment (lipid-lowering, antihypertensive and antidiabetic) and no non-steroidal anti-inflammatory drugs (NSAID) were taken during the study.

Exclusion criteria for the study were as follows: secondary hypertension, white coat hypertension, coronary artery disease, myocardial infarction, revascularisation, stroke, transient ischaemic attack (TIA), peripheral arterial disease (PAD), congestive heart failure, chronic kidney disease (glomerular filtration rate (GFR) $<30 \mathrm{ml} / \mathrm{min}$ ), addiction to alcohol and psychotropic substances, active cancer, congenital or acquired haemostatic disorder, and use of ASA, STE, or other antiplatelet agents within 14 days prior to the study. Additional exclusion criteria for group 2 were hypersensitivity to acetylsalicylic acid and active gastric or duodenal ulcers.

\section{Blood pressure measurements}

In all the patients, during each visit, clinical blood pressure (BP) measurements were performed three times at rest, in a supine position, in standard conditions, and using an upper-arm blood pressure monitor (Omron 705IT). Ambulatory, 24-hour blood pressure measurements (ABPM) were carried out using an A\&D 24-hour ambulatory peripheral blood pressure monitor. The frequency of measurements was every 15 min between 7:00 and 22:00, and every 30 min between 22:00 and 7:00.

\section{VerifyNow test procedure}

Whole blood samples were collected at 1-4 $\mathrm{h}$ from a peripheral vein using a 21-gauge needle in a partial fill $3.2 \%$ citrate vacuum collection tube, after the ingestion of a morning dose of ASA or STE.

The VerifyNow System is a point-of-care turbidimetry-based optical detection system that measures platelet-induced aggregation (Accumetrics Inc., USA). In the study, two types of VerifyNow test kits were used: VerifyNow Aspirin Test and VerifyNow P2Y12. Platelet function was measured at baseline and after 4 weeks of treatment. In group 1, the VerifyNow Aspirin test was assayed. Due to a possible pleiotropic action of STE, in group 2, the Verify Now Aspirin and P2Y12 Verify Now tests were performed.

The VerifyNow Aspirin assay contains lyophilised fibrinogen-coated beads and a platelet agonist - arachidonic acid. It is designed to measure platelet function based on the ability of activated platelets to bind fibrinogen. Fibrinogen-coated microparticles aggregate in whole blood in proportion to the number of unblocked platelet GP IIb/IIla receptors. Light transmittance increases as activated platelets bind and aggregate fibrinogen-coated beads. The instrument measures this change in the optical signal caused by aggregation. Assay results are reported as aspirin reaction units (ARU), which are calculated as a function of the rate of aggregation. Aspirin reaction units values less than 550 indicate an effective result of ASA, while values $>550 \mathrm{ARU}$ indicate no effect of the drug. The VerifyNow P2Y12 test in this assessment measures adenosine phosphate-induced platelet agglutination as an increase in light transmittance and utilises an appropriate algorithm to report values in $\mathrm{P} 2 \mathrm{Y} 12$ reaction units (PRUs) and the percentage of inhibition. A higher PRU count reflects greater $\mathrm{P} 2 \mathrm{Y} 12$-mediated platelet reactivity and indicates a lack of the expected antiplatelet effect.

\section{Statistical analysis}

Statistical analyses were performed with Statistica, version 12.5. (StatSoft, USA). Since the tested data did not meet the assumption of Gaussian distribution (evaluated with the Shapiro-Wilk method) non-parametric methods were applied. The Wilcoxon signed-rank test was used for evaluation of the differences between the initial values and the values obtained after the treatment for factors of body weight composition, blood pressure, and platelet aggregation. To evaluate the differences and correlations between the two independent groups the Mann-Whitney $U$ test and Spearman's rank correlation coefficient $(R s)$ were used respectively. The data presented in the figures and tables included median and interquartile ranges. A $p$-value $<0.05$ was considered significant.

\section{Results}

The detailed demographic data of the studied groups are presented in Table I. There were no statistically significant differences $(p>0.05)$ between these groups for age and body mass index (BMI) (Table I). The baseline blood and lipid profile parameters in both groups did not show statistically significant differences ( $p>0.05$ ), except for a higher triglyceride (TG) concentration in the STE group (Table II; $p<0.05$ ). No changes in these parameters in either of the groups were observed after 4 weeks of therapy. At baseline, the BP values measured in ABPM were significantly $(p<0.05)$ higher in the STE group than in the ASA group (Table I). After 4 weeks of treatment in the ASA group, there was a statistically significant reduction in ARU values measured by the VerifyNow Aspirin test ( $p<$ 0.001 ; Figure 2). Sex and age had no significant impact on ARU values ( $p>0.05)$. In the STE group, there were no statistically significant differences 
Beata Krasinska, Angelika Osińska, Maciej Osinski, Aleksandra Krasinska, Piotr Rzymski, Andrzej Tykarski, Zbigniew Krasiński

Table I. Demographic characteristics of patients treated with ASA or STE at visit 1 (median and interquartile range)

\begin{tabular}{|c|c|c|}
\hline Parameter & $\begin{array}{l}\text { Group } 1 \text { (ASA) } \\
\quad(n=33)\end{array}$ & $\begin{array}{l}\text { Group } 2 \text { (STE) } \\
\quad(n=32)\end{array}$ \\
\hline Female/male, $n$ & $19 / 14$ & $8 / 24$ \\
\hline Age [years] & $53(44-63)$ & $54.5(45.0)$ \\
\hline BMI $\left[\mathrm{kg} / \mathrm{m}^{2}\right]$ & $31.1(27.4-36.3)$ & $27.7(25.3-33.4)$ \\
\hline \multicolumn{3}{|l|}{ BMI group, $n$ : } \\
\hline Normal $\left(18.5-24.9 \mathrm{~kg} / \mathrm{m}^{2}\right)$ & 5 & 6 \\
\hline Overweigh (25.0-29.9kg/m²) & 9 & 11 \\
\hline Obesity $(>30.0$ kg/m²) & 18 & 14 \\
\hline Smokers, $n$ & 4 & 4 \\
\hline $\mathrm{SBP} 24^{\star}[\mathrm{mm} \mathrm{Hg}]$ & $125.0(120.0-137.0)$ & $137.5(122.0-143.0)$ \\
\hline $\mathrm{DBP} 24^{*}[\mathrm{~mm} \mathrm{Hg}]$ & $74.0(70.0-81.0)$ & $80.5(74.0-88.0)$ \\
\hline MAP24* $[\mathrm{mm} \mathrm{Hg}]$ & $91.0(87.0-99.0)$ & $99.0(91.0-107.0)$ \\
\hline HR24 [/min] & $70.0(64.0-77.0)$ & $71.0(66.0-76.0)$ \\
\hline Concomitant lipid-lowering therapy, $n$ & 29 & 28 \\
\hline Concomitant antidiabetic therapy (metformin), $n$ & 2 & 2 \\
\hline Concomitant therapy (anti-hypertensive), $n$ : & 2.9 & 3.2 \\
\hline Diuretics/aldosterone antagonists & $25 / 8$ & $22 / 6$ \\
\hline Angiotensin-converting enzyme inhibitors & 24 & 23 \\
\hline Angiotensin II receptor antagonists & 15 & 13 \\
\hline Calcium antagonists & 11 & 10 \\
\hline$\beta$-blockers & 17 & 16 \\
\hline$\alpha$-blockers & 1 & 2 \\
\hline ARU & $574(541-628)$ & $582(533-604)$ \\
\hline
\end{tabular}

*Statistically significant difference between group 1 (ASA) and group 2 (STE) ( $p<0.05$, Mann-Whitney U test). SBP24 - 24h systolic blood pressure, DBP24 - 24- $h$ diastolic blood pressure, MAP24 - 24- $h$ mean blood pressure, HR24-heart rate in $24 h, B M l-b o d y$ mass index $\left(\mathrm{kg} / \mathrm{m}^{2}\right), A R U$ - aspirin reaction units.

in ARU values between baseline and after 4 weeks of STE treatment $(p>0.05$; Figure 2). However, it was found that the use of STE in obese patients significantly $(p<0.05)$ decreased the ARU values by $8.6 \%$ on average $(95 \% \mathrm{Cl}:-19.5$ to $-1.7 \%$ ) (Figure 3). The STE group was further analysed using the VerifyNow P2Y12 test at the start and after 4 weeks of treatment. In the STE group, there was no statistically significant effect of the extract intake on PRU values. The median PRU values at the start and end of the study were 228 (range: 149-309) and 232 (range: 141-290), respectively. However, after 4 weeks of STE treatment in the obese subgroup, a significant decrease $(p<0.05)$ in the PRU values by $7.5 \%$ on average $(95 \% \mathrm{Cl}$ : -17.6 to $1.8 \%$ ) was observed (Figure 4 ).

There was a statistically significant negative correlation ( $R s=0.41, p<0.05)$ between the change in PRU values and BMI in the STE group (Figure 5). Side effects, such as bleeding, were not recorded in either of the groups. In the presented analysis, ASA resistance was confirmed in $24.2 \%$ of patients (8 from 33 patients), all characterised by $\mathrm{BMI}>30 \mathrm{~kg} / \mathrm{m}^{2}$.

\section{Discussion}

At present, there is a tendency to reduce the role of ASA in primary prevention and to limit the application of ASA in patients with high CVD risk. This is primarily due to the increased risk of bleeding in patients taking ASA [3]. The role of platelets in the formation and progression of atherosclerotic lesions and the development of restenosis after endovascular procedures are well known and documented. The endothelial damage leads to exposure of collagen fibres and plaque adhesion initiating atherogenesis [19]. A meta-analysis of many randomised clinical trials showed a $25 \%$ reduction in the risk of major vascular events with the use of 
Table II. Blood test parameters (median and interquartile range) for group 1 (ASA) and group 2 (STE) at baseline

\begin{tabular}{|lcc|}
\hline Parameter & $\begin{array}{c}\text { Group 1 } \\
\text { ASA }\end{array}$ & $\begin{array}{c}\text { Group 2 } \\
\text { STE }\end{array}$ \\
\hline GLC $[\mathrm{mmol} / \mathrm{l}]$ & $5.6(5.1-6.3)$ & $5.8(5.2-6.2)$ \\
\hline TG $[\mathrm{mmol} / \mathrm{l}]$ & $1.0(0.8-1.4)$ & $1.6(1.1-2.2)$ \\
\hline $\mathrm{LDL}[\mathrm{mmol} / \mathrm{l}]$ & $2.8(2.3-3.4)$ & $2.5(2.1-3.3)$ \\
\hline $\mathrm{TC}[\mathrm{mmol} / \mathrm{l}]$ & $4.9(4.3-5.2)$ & $5.1(4.0-5.6)$ \\
\hline $\mathrm{HDL}[\mathrm{mmol} / \mathrm{l}]$ & $1.3(1.1-1.7)$ & $1.2(1.0-1.5)$ \\
\hline $\mathrm{Na}[\mathrm{mmol} / \mathrm{l}]$ & $141(139-143)$ & $142(140-143)$ \\
\hline $\mathrm{K}[\mathrm{mmol} / \mathrm{l}]$ & $4.3(4.1-4.6)$ & $4.2(3.9-4.6)$ \\
\hline $\begin{array}{l}\text { Serum } \\
\mathrm{creatinine} \\
{[\mu \mathrm{mol} / \mathrm{l}]}\end{array}$ & $79.0(70.9-87.9)$ & $92.1(69.9-111.5)$ \\
\hline $\begin{array}{l}\text { Uric acid } \\
{[\mu \mathrm{mol} / \mathrm{l}]}\end{array}$ & $271.0(196.0-312.0)$ & $313.0(251.0-348.6)$ \\
\hline HGB $[\mathrm{mmol} / \mathrm{l}]$ & $9.0(8.7-9.4)$ & $9.3(8.8-10.0)$ \\
\hline HCT $[\mathrm{l} / \mathrm{ll}]$ & $0.4(0.4)$ & $0.4(0.4-0.5)$ \\
\hline PLT $\left[10^{-9} / \mathrm{l}\right]$ & $241.0(189.0-276.0)$ & $223.0(204.0-257.5)$ \\
\hline
\end{tabular}

*Statistically significant difference between group 1 (ASA) and group 2 (STE) ( $p<0.05$, Mann-Whitney U test). GLC - glucose, TG triglyceride, $L D L-L D L$ cholesterol, $T C$ - total cholesterol, HDL - HDL cholesterol, HGB - haemoglobin, HCT - haematocrit, PLT-platelets.

antiplatelet agents. This is the basis for the wide use of platelet aggregation inhibitors to lower the cardiovascular mortality rate [20]. In industrialised countries, cardiovascular mortality is lowest in the Mediterranean population because of their consumption of a proper diet [21-23]. In the literature, it is emphasised that the main components of this cardioprotective diet are tomatoes and their products with antiplatelet function [24-27]. The bioactivity of tomato extract has been confirmed in both in vitro and ex vivo models [10, 28-33]. The

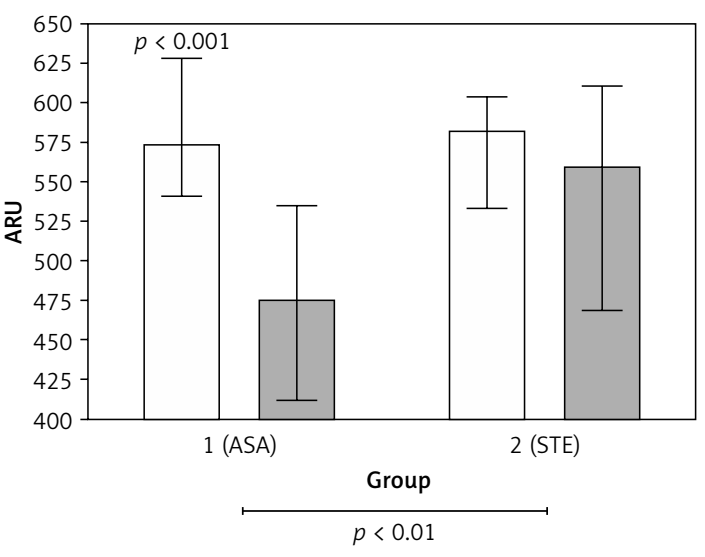

Figure 2. Aspirin reaction units (ARU) (median and interquartile range) in the ASA group and in the STE group at baseline and after 4 weeks of treatment. The decline in the ASA group was statistically significant according to the Wilcoxon signed-rank test. The ARU values differed significantly between ASA and STE groups according to the Mann-Whitney $U$ test

results of many experiments show dose-dependent inhibition of platelet aggregation at $8-23 \%$ after administration of extract of tomato [10, 29]. The STE could be a beneficial food supplement for adults due to multiple actions, such as anti-aggregation, antihypertensive, antidiabetic, antioxidative, antiangiogenic, and protective endothelial effects [13]. Therefore, its use may be indicated in patients with high and very high cardiovascular risk, who are hypersensitive or resistant to ASA. It may also be recommended in subjects who have contraindications for the use of ASA or who have a high risk of complications after antiplatelet treatment (peptic ulcer, gastrointestinal bleeding, and use of medications that increase the risk of bleeding). The study emphasises that target populations, in which STE might be considered, are obese and hypertensive patients with complications or organ damage. The obese patients show
A

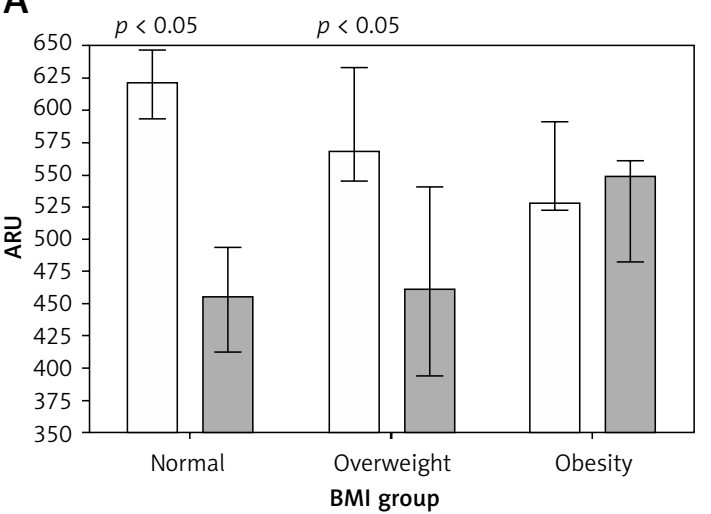

B

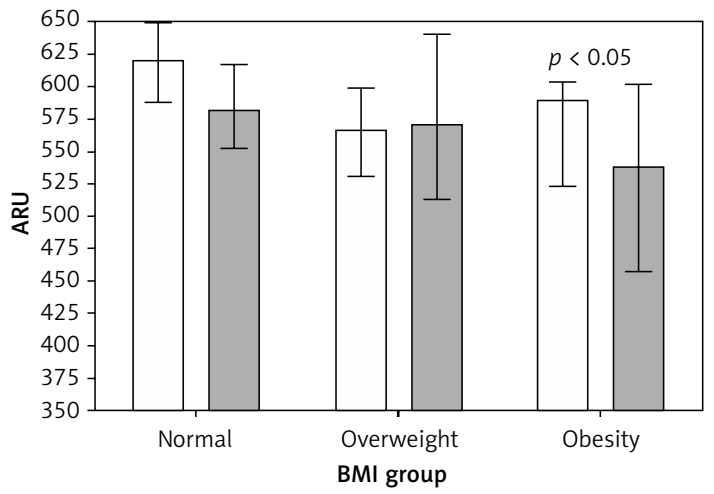

Figure 3. Aspirin reaction units (ARU) (median and interquartile range) in the ASA group (A) and the STE group (B) at baseline (white bars) and after 4 weeks of treatment (grey bars) depending on body mass index (BMI). Reported $p$-value for Wilcoxon signed-rank test. The ARU values did not differ significantly across BMI subgroups in both ASA and STE groups ( $p>0.05$ in both cases; Kruskal-Wallis test) 

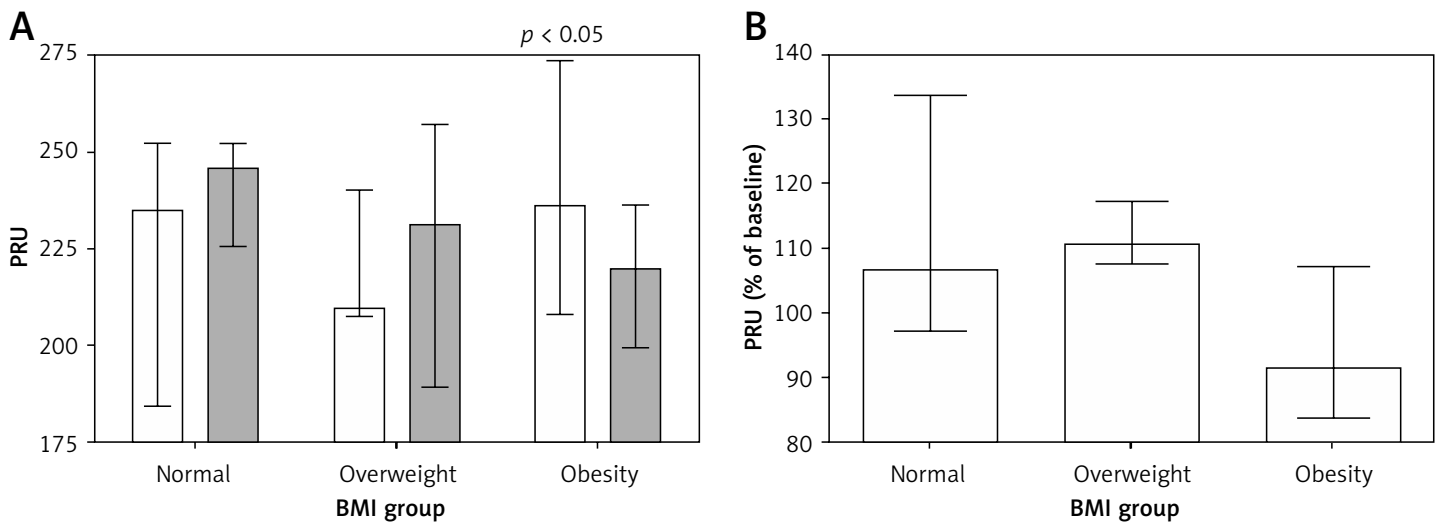

Figure 4. P2Y12 reaction units (PRU) (median and interquartile range) in the STE group in patients with normal nody mass index (BMI) $(n=6)$, overweight $(n=11)$ and obese $(n=14)$ at baseline (white bars) and after 4 weeks of treatment (grey bars). Reported $p$-value for Wilcoxon signed-rank test (A). Changes in PRU after 4 weeks of treatment with STE reported as a percentage of baseline level (median and interquartile range) for patients with different BMI (B). The PRU values did not differ significantly across BMI subgroups ( $p>0.05$; Kruskal-Wallis test)

a decreased response to ASA. This may be due to a higher incidence of ASA resistance in this group. The study indicated that obese individuals might need a higher dose of ASA, administration of another antiplatelet agent, or one-time administration of statins to increase the effectiveness of ASA [34]. The above facts indicate that a decision to include ASA in the primary prevention is becoming more difficult and its use should be balanced. Consequently, this approach creates a therapeutic gap, which in many situations can be filled by other antiplatelet agents. This may be the basis for the search for new antiplatelet agents that will not have as many restrictions as ASA, such as STE.

The present study has revealed that the administration of ASA significantly decreases ARU values (21\% reduction after 4 weeks of treatment). The use of STE only in the obese subgroup significantly decreased ARU values by $8.6 \%$. The antiplatelet effect of the STE was also evaluated in the second method, assessed by the VerifyNow P2Y12 test. A significant decrease in the PRU values after

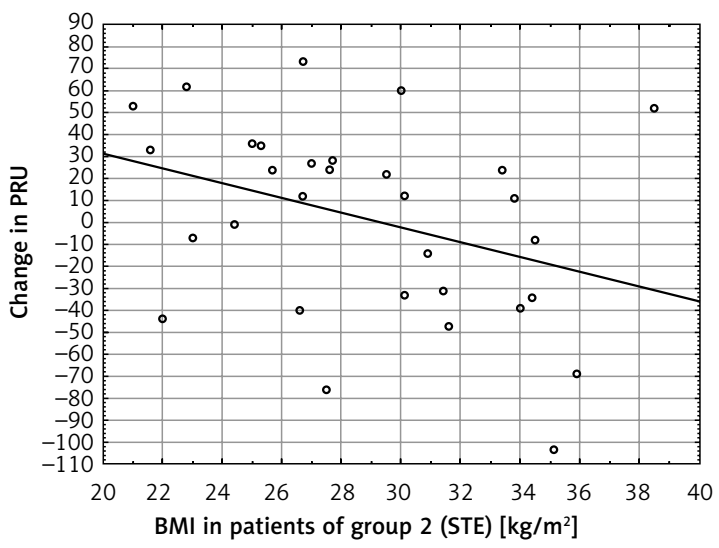

Figure 5. Correlation between body mass index $(\mathrm{BMI})$ and change in $\mathrm{P} 2 \mathrm{Y} 12$ reaction units (PRU) in the STE group after 4 weeks of STE treatment (Spearman $R s=-0.41 ; p<0.05$ )
4 weeks of STE treatment in the obese subgroup was also observed. In the present study, only two pathways for platelet activation were studied using the VerifyNow Aspirin Test and VerifyNow P2Y12. It is known that STE affects multiple mechanisms of platelet aggregation (ADP, collagen, von Willebrand factor, thrombin, inflammatory mediators, P-selectin, and platelet factor 4) [7]. The verification of all possible routes of antiplatelet action of STE was beyond the scope of this analysis. It was shown that three hours after STE administration, there was a significant reduction of ADP-induced platelet aggregation in $97 \%$ of the studied patients in one randomised controlled trial of 90 patients (aged 45-70 years) [29]. This may support the idea that this extract, as a functional food or food supplement, due to its anti-aggregation and anticoagulant properties, could be helpful in the primary prevention of cardiovascular events in patients with high CV risk [13].

It has been demonstrated that the effect of STE on platelet activity is probably weight-dependent, but the study group was too small to draw definitive conclusions. The results may suggest the need for individualisation of antiplatelet therapy according to BMI. One reason for ASA ineffectiveness in patients with high BMI is the phenomenon of ASA resistance. According to various laboratory methods, the presence of ASA resistance in patients with stable coronary disease ranges from $4 \%$ to $60 \%$ [31].

In the present analysis, aspirin resistance was confirmed in $24 \%$ of patients (8 from 33 patients), everyone with $\mathrm{BMI}>30 \mathrm{~kg} / \mathrm{m}^{2}$. Using multiple electrode aggregometry and VerifyNow Larsen et al. found that a high BMI was an independent determinant of increased platelet aggregation, which is consistent with the results found in healthy individuals, as well as in patients with ischaemic heart disease [31-33]. Obesity affects pharmacokinetics on the basis of changes in 
the volume of distribution, regional blood flow, and mechanisms of renal and liver elimination [35-37]. The evidence suggests that obesity, regardless of additional comorbidities, may be associated with decreased efficacy of antiplatelet agents [38]. This conclusion can be partially explained by the faster inactivation of ASA due to the modification of obesity-related pharmacokinetic mechanisms [39]. Elevated leptin levels in obesity may reduce the effectiveness of ASA by increasing pro-thrombotic effects [40]. In addition, the present study revealed a significant negative correlation between change in PRU values and $\mathrm{BMI}(R s=-0.41, p<0.05)$ in the STE group. This correlation indicates that the greater the weight of patients is, the greater is the receptor $\mathrm{P} 2 \mathrm{Y} 12$ inhibition (Figure 5). The obtained results are different from those published by O'Kennedy et al., who reported no such correlation [13]. Different results show the need to verify the response to ASA in this group of patients and its dependence on BMI especially. Even though the findings of the study are promising, there are certain limitations that need to be recognised. Firstly, the conducted investigation was a single-centre study, including only a small population of hypertensive patients with high cardiovascular risk. Additionally, only two types of tests for assessing platelet function were used: the VerifyNow Aspirin Test and the VerifyNow P2Y12 Test. Verification of all possible routes of antiplatelet action of STE was beyond the scope of this analysis. A future randomised study with clinical end-points would be required to substantiate our findings.

In conclusion, the present data demonstrate that the effect of antiplatelet agents in patients with hypertension and with high cardiovascular risk is heterogeneous and may be weight dependant. Patients with $\mathrm{AH}$ and obesity constitute a group that could potentially benefit from STE treatment. STE, which contains cardioprotective components, could be a beneficial agent in the prevention of thrombosis and inflammation associated with plaque activation in hypertensive and obese patients. The present data suggest that STE may be appropriate for use as a dietary antiplatelet agent in the primary prevention of cardiovascular diseases.

\section{Conflict of interest}

The authors declare no conflict of interest.

\section{References}

1. Sosnowska B, Penson P, Banach M. The role of nutraceuticals in the prevention of cardiovascular disease. Cardiovasc Diagn Ther 2017; 7 (Suppl 1): S21-31.

2. Cicero A, Colletti A, Bajraktari G, et al. Lipid lowering nutraceuticals in clinical practice: position paper from an International Lipid Expert Panel. Arch Med Sci 2017; 13: 965-1005

3. Antithrombotic Trialists' (ATT) Collaboration, et al. Aspirin in the primary and secondary prevention of vascular disease: collaborative meta-analysis of individual participant data from randomised trials. Lancet 2009; 373: 1849-60.

4. Mancia G, Fagard R, Narkiewicz K, et al. 2013 ESH/ESC Guidelines for the management of arterial hypertension: the Task Force for the management of arterial hypertension of the European Society of Hypertension (ESH) and of the European Society of Cardiology (ESC). J Hypertens 2013; 31: 1281-357.

5. Piepoli MF, Hoes AW, Agewall S, et al. 2016 European Guidelines on cardiovascular disease prevention in clinical practice: The Sixth Joint Task Force of the European Society of Cardiology and Other Societies on Cardiovascular Disease Prevention in Clinical Practice (constituted by representatives of 10 societies and by invited experts) Developed with the special contribution of the European Association for Cardiovascular Prevention \& Rehabilitation (EACPR). Eur Heart J 2016; 37: 2315-81.

6. Komosa A, Rzymski P, Perek B, et al. Platelets redox balance assessment: current evidence and methodological considerations. Vascular Pharmacol 2017; 93-95: 6-13.

7. O'Kennedy N, Raederstorff D, Duttaroy AK. “Fruitflow (®): the first European Food Safety Authority-approved natural cardio-protective functional ingredient. Eur J Nutr 2017; 56: 461-82.

8. Fuentes E, Forero-Doria O, Carrasco G, et al. Effect of tomato industrial processing on phenolic profile and antiplatelet activity. Molecules 2013; 18: 11526-36.

9. European Food Safety Authority (EFSA), Bresson JL, Flynn A, Heinonen $M$, et al. Water-soluble tomato concentrate (WSTC I and II) and platelet aggregation. EFSA J 2009; 7.

10. Wożakowska-Kapłon B, Filipiak KJ, Mamcarz A, Narkiewicz K, Tykarski A, Widecka K. Miejsce wystandaryzowanego ekstraktu z pomidorów w prewencji pierwotnej schorzeń układu sercowo-naczyniowego. Czy i kiedy stanowi alternatywę dla kwasu acetylosalicylowego? Stanowisko grupy ekspertów. Folia Cardiol 2015; 10 : 100-5.

11. Navarrete S, Alarcón M, Palomo I. Aqueous extract of tomato (Solanum lycopersicum L.) and ferulic acid reduce the expression of TNF-alpha and IL-1 beta in LPS-activated macrophages. Molecules 2015; 20: 15319-29.

12. Biswas D, Uddin MM, Dizdarevic LL, et al. Inhibition of angiotensin-converting enzyme by aqueous extract of tomato. Eur J Nutr 2014; 53: 1699-706.

13. O'Kennedy N, Crosbie L, van Lieshout M, Broom Jl, Webb DJ, Duttaroy AK. Effects of antiplatelet components of tomato extract on platelet function in vitro and ex vivo: a time- course cannulation study in healthy humans. Am J Clin Nutr 2006; 84: 570-9.

14. Faridi KF, Lupton JR, Martin SS, et al. Vitamin D deficiency and non-lipid biomarkers of cardiovascular risk. Arch Med Sci 2017; 13; 732-7.

15. Ghomari-Boukhatem H, Bouchouicha A, Mekki K, Chenni K, Belhadj M, Bouchenak M. Blood pressure, dyslipidemia and inflammatory factors are related to body mass index in scholar adolescents. Arch Med Sci 2017; 13: 46-52.

16. Ciccone MM, Cortese F, Gesualdo M, et al. Dietary intake of carotenoids and their antioxidant and anti-inflammatory effects in cardiovascular care. Mediators Inflamm 2013; 2013: 782137. 
17. Hu FB, Rimm EB, Stampfer MJ, Ascherio A, Spiegelman D, Willett WC. Prospective study of major dietary patterns and risk of coronary heart disease in men. Am J Clin Nutr 2000; 72: 912-21.

18. Plaza L, Sánchez-Moreno C, Ancos BD, Cano MP. Carotenoid content and antioxidant capacity of Mediterranean vegetable soup (gazpacho) treated by high-pressure/temperature during refrigerated storage. Eur Food Res Technol 2006; 223; 210-5.

19. Cassar K, Bachoo P, Brittenden J. The role of platelets in peripheral vascular disease. Eur J Vasc Endovasc Surg 2003; 25: 6-15.

20. Cronenwett J, Johnston K. Rutherford's Vascular Surgery. $8^{\text {th }}$ ed. Vol. 2. Elsevier Expert Consult USA, 2014.

21. Tektonidis TG, Åkesson A, Gigante B, Wolk A, Larsson SC. Adherence to a Mediterranean diet is associated with reduced risk of heart failure in men. Eur J Heart Fail 2016; 18: 253-9.

22. Tektonidis TG, Åkesson A, Gigante B, Wolk A, Larsson SC. A Mediterranean diet and risk of myocardial infarction, heart failure and stroke: a population-based cohort study. Atherosclerosis 2015; 243: 93-8.

23. Rees K, Hartley L, Flowers N, et al. Mediterranean' dietary pattern for the primary prevention of cardiovascular disease. Cochrane Database Syst Rev 2013; 8: CD009825.

24. Burton-Freeman BM, Sesso HD. Whole food versus supplement: comparing the clinical evidence of tomato intake and lycopene supplementation on cardiovascular risk factors. Adv Nutr 2014; 5: 457-85.

25. Jacques PF, Lyass A, Massaro JM, Vasan RS, Agostino RBD. Relationship of lycopene intake and consumption of tomato products to incident CVD. Br J Nutr 2013; 110: $545-51$

26. Ghavipour M, Saedisomeolia A, Djalali M, et al. Tomato juice consumption reduces systemic inflammation in overweight and obese females. Br J Nutr 2013; 109: 2031-5.

27. Canene-Adams K, Campbell JK, Zaripheh S, Jeffery EH, Erdman JW. The tomato as a functional food. J Nutr 2005; 135: 1226-30.

28. Dutta-Roy AK, Crosbie L, Gordon MJ. Effects of tomato extract on human platelet aggregation in vitro. Platelets 2001; 12: 218-27.

29. O'Kennedy N, Crosbie L, Whelan S, et al. Effects of tomato extract on platelet function: a double-blinded crossover study in healthy humans. Am J Clin Nutr 2006; 84: 561-9.

30. Lazarus SA, Bowen K, Garg ML. Tomato juice and platelet aggregation in type 2 diabetes. JAMA 2004; 292: 805-6.

31. Rodríguez-Azúa R, Treuer A, Moore-Carrasco R, et al. Effect of tomato industrial processing (different hybrids, paste, and pomace) on inhibition of platelet function in vitro, ex vivo, and in vivo. J Med Food 2014; 17: 505-11.

32. Fuentes EJ, Astudillo LA, Gutiérrez MI, et al. Fractions of aqueous and methanolic extracts from tomato (Solanum lycopersicum L.) present platelet antiaggregant activity. Blood Coagul Fibrinolysis 2012; 23: 109-17.

33. Fuentes E, Palomo I. Relationship between platelet PPARs, CAMP levels, and P-selectin expression: antiplatelet activity of natural products. Evid Based Complement Alternat Med 2013; 2013: 861786

34. Bordeaux BC, Qayyum R, Yanek LR, et al. Effect of obesity on platelet reactivity and response to low-dose aspirin. Prev Cardiol 2010; 13: 56-62.
35. Peace A, McCall M, Tedesco T, et al. The role of weight and enteric coating on aspirin response in cardiovascular patients. J Thromb Haemost 2010; 8: 2323-5.

36. Hanley MJ, Abernethy DR, Greenblatt DJ. Effect of obesity on the pharmacokinetics of drugs in humans. Clin Pharmacokinet 2010; 49: 71-87.

37. Bonello-Palot N, Armero S, Paganelli F, et al. Relation of body mass index to high on-treatment platelet reactivity and of failed clopidogrel dose adjustment according to platelet reactivity monitoring in patients undergoing percutaneous coronary intervention. Am J Cardiol 2009; 104: 1511-5.

38. Mayer K, Orban M, Bernlochner I, et al. Predictors of antiplatelet response to prasugrel during maintenance treatment. Platelets 2015; 26: 53-8.

39. Rocca B, Petrucci G. Variability in the responsiveness to low-dose aspirin: pharmacological and disease-related mechanisms. Thrombosis 2012; 2012; 376721.

40. Nakata M, Yada T, Soejima N, Maruyama I. Leptin promotes aggregation of human platelets via the long form of its receptor. Diabetes 1999; 48; 426-9. 